\title{
The role of stimulus context on apparent duration
}

\author{
H. R. SCHIFFMAN, DOUGLAS J. BOBKO, and JACK G. THOMPSON \\ Rutgers, The State University of New Jersey, New Brunswick, New Jersey 08903
}

\begin{abstract}
The influence of stimulus context on apparent duration was investigated using direct scaling procedures. The results indicate that the use of such scaling methods minimizes contextual effects in judged duration. The results also suggest that apparent duration is a continuous linear function of physical duration.
\end{abstract}

The effect of the established context of stimuli within a graded stimulus series on the observer's criterion of judgment for a variety of sensory-perceptual modalities has been extensively examined and reported (e.g., Helson, 1964; Parducci, 1974). However, the effect of the range of magnitude of stimuli for temporal experience or apparent duration has been the subject of sparse empirical study. Several investigators (Braud \& Holborn, 1966; Goldstone, Lhamon, \& Boardman, 1957; Schiffman \& Bobko, 1974, 1977) have suggested that the range of stimuli affects the judgment of apparent duration. That is to say, the perceived duration of an interval is subject to the "regression" or "central tendency effect of judgment" (Hollingworth, 1910). However, such relative effects have been either subsidiarily reported (Stevens \& Greenbaum, 1966) or demonstrated with standard durations on the order of $1 \mathrm{sec}$ (Goldstone et al., 1957; Goldstone, Boardman, \& Lhamon, 1959). Additionally, the role of the range of stimulus magnitudes presented in the experimental context of direct scaling of apparent duration has not yet been systematically explored and remains unclear; the majority of previous investigators reporting regression effects have employed the method of production or reproduction (see Treisman, 1963, and Doehring, 1961 , for a review).

The present experiment was performed to clarify this issue. Specifically, three stimulus series of increasing duration were designed so that the longest stimulus of Series $1(25 \mathrm{sec})$ was the midvalue stimulus of Series 2 and the briefest stimulus of Series 3. Thus, it was possible to examine directly the role of stimulus series membership (context) on apparent duration. It was provisionally hypothesized that contextual factors would exert a measurable influence on perceived duration. Specifically, it was presumed that the perceived magnitude of the stimulus common to all series would reliably differ.

This study was supported by funds from the Research Council of Rutgers, State University of New Jersey (Grant 07-2109), and by funds from the Charles and Johanna Busch Memorial Grant.

\section{METHOD}

\section{Subjects}

Thirty undergraduate volunteers from an introductory course in psychology served as subjects.

\section{Stimuli}

Three series of temporal durations were employed. In Series 1 , the intervals ranged from 1.0 to $25 \mathrm{sec}$, in Series 2 the intervals ranged from 13 to $37 \mathrm{sec}$, and in Series 3 the intervals ranged from 25 to $49 \mathrm{sec}$. In all three series the stimulus intervals varied in equal steps of $3 \mathrm{sec}$, thereby producing a total of nine stimuli for each series. A small black $x$ which subtended a visual angle of $1 \mathrm{deg} 14 \mathrm{~min}$ served as the stimulus target. This target was constructed of $1.5-\mathrm{mm}$-wide black graph tape mounted on a card of white poster board. During testing, the midpoint of the target was congruent with the center of the presentation field. The stimulus intervals were defined by the presentation of the stimulus target.

\section{Apparatus}

The main testing apparatus was a two-channel tachistoscope (Gerbrands Model T1C). The tachistoscope was mounted on top of a 71-cm-high table and the entire apparatus, except for the viewing aperture of the tachistoscope, was concealed from the subjects. The rated light output of the tachistoscope was 105 lumens. Room illumination was measured at $79 \mathrm{~cd} \mathrm{~m}^{-2}$.

\section{Design and Procedure}

A between-groups design was employed. Ten subjects were randomly assigned to each of the three experimental conditions, that is, each of the three durations series.

The psychophysical method of magnitude estimation was employed. Wristwatches were removed prior to the experimental session and subjects were read the following instructions: "The purpose of this experiment is to investigate time perception. A small black $x$ will be presented for different intervals of time. I want you to estimate how long you think the $\mathrm{x}$ is on for each interval to the nearest second and fraction of a second. Try to estimate the length of the first interval as accurately as you can. Thereafter, try to keep your judgments proportional. Please do not tap or count during the experiment. Do you have any questions?"

Subjects were then presented with all nine intervals of a series in random order. A different randomization order was employed for each subject.

\section{RESULTS AND DISCUSSION}

For each experimental condition, the data were averaged across subjects by computing the geometric 


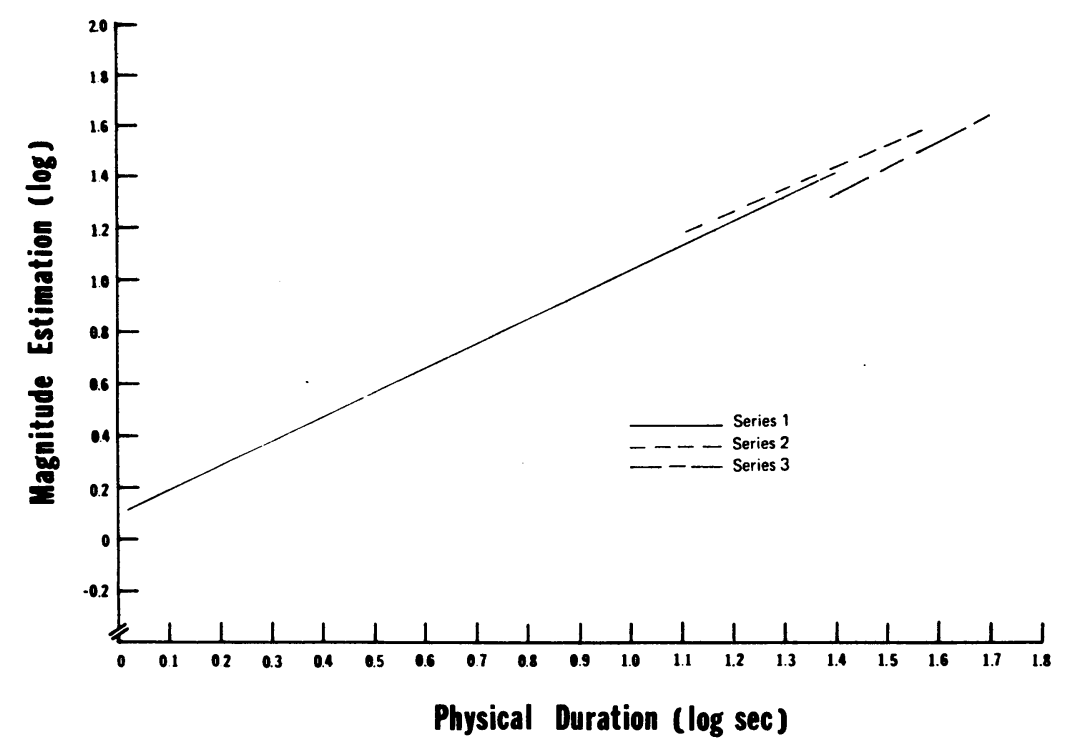

Figure 1. Logarithmic plots of duration estimates by physical duration for the three experimental conditions. Durations intervals were defined by the presentation of a visual target.

mean of the estimates for each presentation interval. Straight lines were fitted by regression analysis to the log duration estimates as a function of log physical duration, as shown in Figure 1; the slopes, correlation coefficients, and $F$ values from the regression analyses for these functions are shown in Table 1. Together, the high correlation coefficients and significant $F$ scores (each at $\mathrm{p}<.01$ ) suggest that the relationship between the logarithms of physical and judged duration is linear and thus conforms to a power function. In the two series of shorter intervals, apparent duration was a slightly decelerated function of physical duration, while in the series of longer intervals ( 25 to $49 \mathrm{sec}$ ) apparent duration was a slightly accelerated function of physical duration. In order to test whether this difference was significant, a regression analysis was performed on each subject's estimates and an analysis of variance was performed on the resulting exponents. However, the main effect of stimulus series was not significant. In short, since the exponents for all three power functions approximate unity, judged duration may simply be described as a continuous linear function of physical duration for the intervals reported herein. This finding is in agreement

Table 1

Power Function Slopes Correlation Coefficients and $F$ Values by Stimulus Series

\begin{tabular}{lccr}
\hline & & Correlation & \\
& Slope & Coefficient & \multicolumn{1}{c}{$\mathrm{F}(1,3)$} \\
\hline Series 1 & .93 & .998 & 1846.01 \\
Series 2 & .90 & .992 & 406.83 \\
Series 3 & 1.05 & .950 & 65.49 \\
\hline
\end{tabular}

Note-Geometric mean $=.96$. with a number of other investigators (Ross \& Katchmar, 1951; Stevens, 1960; Stevens \& Greenbaum, 1966), each of whom reported a direct and linear function in duration judgment for the auditory modality.

In order to assess the influence of context on the subjects' judgments, an analysis of variance was performed on the estimates of the duration of the $25-\mathrm{sec}$ stimulus interval. Since this interval was the longest stimulus in Series 1, the median stimulus in Series 2, and the briefest stimulus in Series 3, it was hypothesized that any central tendency effect would be most pronounced and identifiable for this interval. Specifically, according to Vierordt's law (see Underwood, 1966, p. 57), this interval should appear relatively shorter in Series 1 and longer in Series 3, that is, the duration estimates should regress toward the midrange value of the duration series. However, the main effect of stimulus series was not significant $[F(2,27)=1.43]$. This finding stands in contrast to other reports of contextual or regression effects (e.g., Bobko et al., 1977) obtained with the method of reproduction and in between-groups design. In summary, then, the results of the present study may be taken to indicate that the utilization of direct scaling procedures on apparent duration minimizes contextual or regression effects.

\section{REFERENCES}

Bobko. D. J.. Schiffman, H. R., Castino, R. J.. \& Chiapetta, W. Contextual effects in duration experience. American Journal of Psychology, in press.

Braud. W. G..\& Holborn. S. W. Temporal context effects with two judgmental languages. Psychonomic Science. 1966. 6. $151-152$. 
Doehering. D. G. Accuracy and consistency of time-estimation by by four methods of reproduction. American Journal of Psychology. 1961. 74, 27-35.

Goldstone, S., Boardman, W. K., \& Lhamon, W. T. Intersensory comparisons of temporal judgments. Journal of Experimental Psychology, 1959, 57, 243-249.

Goldstone. S., Lhamon, W. T., \& Boardman, W. K. The time sense: Anchor effects and apparent duration. Journal of Psychology, 1957, 44. 145-153.

Helson. H. Adaptation-level theory. New York: Harper \& Row, 1904.

HollingWORTH, H. L. The central tendency of judgment. Journal of Philosophical Psychology, 1910, 7, 461-469.

PARDucci. A. Contextual effects: A range-frequency analysis. In E. C. Carterette \& M. P. Friedman (Eds.), Handbook of perception (Vol. 2). New York: Academic Press, 1974.

Ross. S.. \& KatchmaR, L. The construction of a magnitude function for short time-intervals. American Journal of Psichology. 1951, 64, 397-401.
Schiffman. H. R., \& Boвко, D. J. Effects of stimulus complexity on the perception of brief temporal intervals. Journal of Experimental Psychology, 1974, 103, 156-159.

Schiffman, H. R..\& BoвKo, D. J. The role of stimulus familiarity and numerosity in the perception of brief temporal intervals. American Journal of Psychology, 1977, 90, 85-93.

Stevens. S. S. The psychophysics of sensory function. American Scientist, 1960, 48, 226-253.

Stevens, S. S., \& Greenbaum, H. B. Regression effect in psychological judgments. Perception \& Psychophysics, 1966, 1. 439-446.

Treisman, M. Temporal discrimination and the indifference interval: Implications for a model of the "internal clock." Psychological Monographs, 1966, 77, 1-31.

UNDERWOOD, B. J. Experimental psychology. New York: Appleton-Century-Crofts, 1966.

(Received for publication August 19, 1977.) 